\title{
Tricholoma matsutake Aqueous Extract Induces Hepatocellular Carcinoma Cell Apoptosis via Caspase-Dependent Mitochondrial Pathway
}

\author{
Yanzhen Wang, ${ }^{1,2}$ Yiling Chen, ${ }^{1,3}$ Xinrui Zhang, ${ }^{2}$ Guangsheng Cai, ${ }^{2}$ \\ Shengshu An, ${ }^{2}$ Xue Wang, ${ }^{2}$ Lirong Teng, ${ }^{1,2}$ and Di Wang ${ }^{1,2}$ \\ ${ }^{1}$ Zhuhai College of Jilin University, Jilin University, Zhuhai 519000, China \\ ${ }^{2}$ School of Life Sciences, Jilin University, Jilin 130012, China \\ ${ }^{3}$ Southern Research Institute, Jilin University, Zhuhai 519000, China \\ Correspondence should be addressed to Lirong Teng; tenglirong@jlu.edu.cn and Di Wang; jluwangdi@gmail.com
}

Received 29 June 2016; Accepted 9 November 2016

Academic Editor: Emanuele Marzetti

Copyright (c) 2016 Yanzhen Wang et al. This is an open access article distributed under the Creative Commons Attribution License, which permits unrestricted use, distribution, and reproduction in any medium, provided the original work is properly cited.

Tricholoma matsutake, one of widely accepted functional mushrooms, possesses various pharmacological activities, and its antitumor effect has become an important research point. Our study aims to evaluate the cytotoxicity activities of T. matsutake aqueous extract (TM) in HepG2 and SMMC-7721 cells. In in vitro experiments, TM strikingly reduced cell viability, promoted cell apoptosis, inhibited cell migration ability, induced excessive generation of ROS, and caused caspases cascade and mitochondrial membrane potential dissipation in hepatocellular carcinoma cells. In in vivo experiments, 14-day TM treatment strongly suppressed tumor growth in HepG2 and SMMC-7721-xenografted nude mice without influence on their body weights and liver function. Furthermore, TM increased the levels of cleaved poly-ADP-ribose polymerase (PARP), Bad, and Bax and reduced the expressions of B-cell lymphoma 2 (Bcl-2) in treated cells and tumor tissues. All aforementioned results suggest that caspase-dependent mitochondrial apoptotic pathways are involved in TM-mediated antihepatocellular carcinoma.

\section{Introduction}

As the most common organ malignancy worldwide, hepatocellular carcinoma (HCC) generally carries a poor prognosis [1]. According to the latest statistics, about 600,000 patients are diagnosed with HCC around the world each year, and some of them die within 7-8 months after diagnosis [2]. Till now, under advanced medical situation, multiple therapeutic options have been applied for HCC therapy; however, these options show various adverse effects including immune system disorders and liver toxicity [3]. Therefore, more effective alternative therapies or medicines with fewer adverse effects for HCC curing are urgently required.

Natural products, with low toxicity and strong pharmacological activities, have become one of the most popular strategies for antitumor agent development [4]. In our group, we have successfully confirmed the proapoptotic properties of Cordyceps militaris in hepatocellular carcinoma and breast cancer cells related to caspase-dependent mitochondrial pathway [5]. Tricholoma matsutake, a highly valued ectomycorrhizal mushroom, exhibits various biological activities such as antimicroorganism, immunostimulation, and antioxidation properties [6]. It has been confirmed that T. matsutake strongly inhibits HeLa and HepG2 cell proliferation [7]. In human promyelocytic leukemia cells, T. matsutake induces significant damage by activating caspase-related pathway [8]. In in vivo mouse models, T. matsutake polysaccharides suppress S180 tumor growth, which is believed to be a consequence of the stimulation on cell-mediated immune responses [9]. Although the antitumor effects of T. matsutake have already been clarified in several previous researches, its underlying mechanisms of antihepatocellular carcinoma are still unknown.

During cell apoptosis process, abnormal alternations on oxidation system, mitochondrial function, and proapoptotic and antiapoptotic protein levels were observed [10-12]. 
Mitochondria apoptosis, a well-known death signaling pathway, accompanies mitochondrial depolarization, cytochrome C (Cyt C) overrelease, and caspase-3 activation. Initiator caspase, especially caspase- 8 and caspase- 9 , can catalyze proteolytic maturation of caspase-3, which is recognized as an important effector protease [13]. Interestingly, in extrinsic apoptosis, the activation of caspase- 8 increases mitochondrial membrane permeability [14]. On the other hand, hyperlevel of oxidative stress leads to the modification of amino acid residues thereby causing DNA mutations and cell apoptosis [15]. The overgeneration of reactive oxygen species (ROS) causes intracellular oxidative stress and further aggravates mitochondrial depolarization [16].

Based on these encouraging results, the purpose of this study aims to investigate the antihepatocellular carcinoma activity of T. matsutake in HepG2 and SMMC-7721 cells systematically. Through in vitro and in vivo experiments, the proapoptotic effects of T. matsutake and underlying mechanisms related to mitochondrial apoptotic pathways were explored.

\section{Materials and Methods}

2.1. T. matsutake Aqueous Extract Preparation. T. matsutake mycelium obtained via liquid submerge fermentation [17] was extracted at $95^{\circ} \mathrm{C}$ for $3 \mathrm{~h}$ in double distilled (DD) water. After concentration using evaporator, the extract was freezedried and named TM for further experiments. The content of polysaccharides and total proteins was detected via phenolsulfuric acid method [18] and Kjeldahl method [19]. TM contains $29.9 \%$ of polysaccharides and $19.6 \%$ of total proteins.

2.2. Cell Culture. Human HCC cell lines HepG2 (CRL11997; ATCC, USA) and SMMC-7721 (BNCC33; CCTCC, China) were maintained in Dulbecco's Modified Eagle Media (DMEM) supplemented with 10\% fetal bovine serum (FBS), 100 units/mL penicillin, and $100 \mu \mathrm{g} / \mathrm{mL}$ streptomycin under a humidified atmosphere containing 5\%/95\% CO2/air at $37^{\circ} \mathrm{C}$. All reagents were obtained from Invitrogen, USA.

2.3. MTT Assay. To test the effect of TM on cell viability, a quantitative colorimetric assay with 3-(4,5)-dimethylthiahiazo(-z-y1)-3,5-di-phenytetrazoliumbromide (MTT) was applied. Briefly, HepG2 and SMMC-7721 cells were seeded into 96-well plates at $1 \times 10^{4}$ cells in $100 \mu \mathrm{L}$ of medium per well. After incubation with $1-5 \mathrm{mg} / \mathrm{mL}$ of TM for $24 \mathrm{~h}$ and $48 \mathrm{~h}$, cells were incubated with $0.5 \mathrm{mg} / \mathrm{mL}$ of MTT for $4 \mathrm{~h}$ at $37^{\circ} \mathrm{C}$ in darkness. After removing the culture medium, $100 \mu \mathrm{L}$ of dimethylsulfoxide (DMSO) was added to dissolve formazan crystals within cells. The absorbance was then measured using Synergy ${ }^{\mathrm{TM}}$ Microplate Reader (BioTek Instruments, Winooski, VT) at a wavelength of $490 \mathrm{~nm}$.

2.4. Colony Formation Assays. Colony formation was detected by crystal violet staining. Cells were seeded into 6-well plate at density of $5 \times 10^{4}$ cells/well and incubated with 1$5 \mathrm{mg} / \mathrm{mL}$ TM for consecutive 7 days. Completed medium contained agents were changed every two days. Treated cells were fixed in $4 \%$ paraformaldehyde for $10 \mathrm{~min}$ and then stained with $0.1 \%$ crystal violet for $60 \mathrm{~min}$. After three washes with phosphate buffered saline (PBS), cells were subsequently photographed. The experiments were repeated for three times.

2.5. Migration Assay. $1 \times 10^{5}$ cells/well were seeded into 6well plates, cultured to over $90 \%$ confluence, and then scraped with a needle. After $24 \mathrm{~h}$ treatment with TM, migratory ability was evaluated by measuring the distance of cell migrating. The experiments were repeated for three times.

2.6. Apoptotic Rate Assay. Cells were seeded into 6-well plates at $4 \times 10^{5}$ cells per well. After $24 \mathrm{~h}$ TM treatment at doses of 2.5 and $5 \mathrm{mg} / \mathrm{mL}$, cells were stained with propidium iodide (PI) and Annexin V for $20 \mathrm{~min}$ at room temperature in darkness. The intensity of fluorescence was measured utilizing Muse $\mathrm{T}^{\mathrm{TM}}$ Cell Analyzer from Millipore (Billerica, MA) following manufacturer's instructions. The experiments were repeated for three times.

2.7. Assessment of Caspases Activities. Cells incubated with 2.5 and $5 \mathrm{mg} / \mathrm{mL}$ of TM for $24 \mathrm{~h}$ were harvested using lysis buffer. After detection of protein concentrations, the activities of caspase-3, caspase-8, and caspase- 9 were measured via related commercial kits (Nanjing Jiancheng Bioengineering Institute, Nanjing, China).

2.8. Assessment of Intracellular ROS Levels. $2^{\prime}-7^{\prime}$-Dichlorodihydrofluorescein diacetate (DCFH-DA, Sigma-Aldrich, USA) staining was applied to analyze intracellular ROS levels. After $6 \mathrm{~h}$ incubation with TM at doses of 2.5 and $5 \mathrm{mg} / \mathrm{mL}$, cells were incubated with $10 \mu \mathrm{M}$ of DCFH-DA for $15 \mathrm{~min}$. After three washes with PBS, the changes of green florescent intensity were examined under Nikon Eclipse TE 2000$S$ fluorescence microscope (20x; CCD camera; Nikon Instruments Inc., Japan).

2.9. Assessment of Mitochondrial Membrane Potential (MMP). In our experiment, the changes of MMP were analyzed by $5,5^{\prime}, 6,6^{\prime}$-tetrachloro-1,1',3,3' tetraethylbenzimidazolylcarbocyanine iodide (JC-1; Calbiochem, USA) staining. Cells were seeded into 6 -well plates at $1 \times 10^{5}$ cells/well and incubated with 2.5 and $5 \mathrm{mg} / \mathrm{kg}$ of TM for $6 \mathrm{~h}$, following with another $15 \mathrm{~min}$ exposure to $2 \mu \mathrm{M}$ of $\mathrm{JC}-1$ at $37^{\circ} \mathrm{C}$ in darkness. After three washes, fluorescent color changes were analyzed using fluorescent microscopy under Nikon Eclipse TE 2000-S fluorescence microscope (20x; CCD camera; Nikon Instruments Inc., Japan).

2.10. HepG2- and SMMC-7721-Xenografted Tumor Mouse Models. The animal experimental protocol was approved by the Animal Ethics Committee of Jilin University. Six-weekold male BALB/c nude mice (Chares River Experimental Animal Technical Co., Ltd., Beijing, China) were housed in groups of three in clear plastic cages and maintained on a $12 \mathrm{~h}$ light/dark cycle at $23 \pm 1^{\circ} \mathrm{C}$ with water and food available ad libitum. 
HepG2 and SMMC-7721 cells were harvested at mid$\log$ phase, and a total number of $5 \times 10^{6}$ cells $/ 100 \mu \mathrm{L}$ were subcutaneously injected into the right back near hind leg of each mouse. After 3 days, mice were divided into two groups ( $n=3$ each) randomly and treated with $1 \mathrm{~g} / \mathrm{kg}$ of TM and $0.9 \%$ of saline solution every other day continuously for 14 days. Body weight and tumor dimensions were recorded before drug treatment. Tumor size was calculated as following equation: length $(\mathrm{mm}) \times$ width $(\mathrm{mm})^{2} \times 0.5$. At the end of the experiment, the liver and tumor tissues were collected and stored at $-80^{\circ} \mathrm{C}$.

2.11. Histopathological Examination. Liver tissues were immerged in $4 \%$ of paraformaldehyde for $24 \mathrm{~h}$ and dehydrated via $50 \%-100 \%$ ethanol step by step. After permeabilization with xylene, the samples were embedded in wax and cut into serial sections at $5 \mu \mathrm{m}$ thickness using microtome (Leica, Germany). Sections were immerged with fresh xylene for $10 \mathrm{~min}$, hydrated with gradient ethanol from $100 \%$ to $70 \%$, and finally washed with DD water [20]. Haematoxylin and eosin staining (H\&E staining) was applied to examine histopathology of liver.

2.12. Western Blot Analysis. Collected cells, which were treated with 2.5 and $5 \mathrm{mg} / \mathrm{mL}$ of TM for $24 \mathrm{~h}$, and collected tumor tissues were lysed by RIPA buffer (Sigma-Aldrich, USA) containing $1 \%$ protease inhibitor cocktail (SigmaAldrich, USA) and $2 \%$ phenylmethanesulfonyl fluoride (PMSF; Sigma-Aldrich, USA). Protein concentrations were determined using Bradford method. $40 \mu \mathrm{g}$ of proteins was separated by $10-12 \%$ SDS-PAGE gels and then transferred electrophoretically onto PVDF membranes. The transferred membranes were blocked in 5\% bull serum albumin (BSA) for $4 \mathrm{~h}$ and then blotted with the following primary antibodies at $4^{\circ} \mathrm{C}$ overnight at dilution of 1:1000: cleaved poly(ADP-ribose) polymerase (cleaved-PARP) (ab32064), Bad (ab129192), Bax (ab7977), B-cell lymphoma-2 (Bcl-2) (ab32124), and glyceraldehyde-3-phosphate dehydrogenase (GAPDH) (ab8245) (Abcam, Cambridge, MA), followed by incubation with horseradish peroxidase-conjugated secondary antibodies diluted at 1:2000 (Santa Cruz, USA). ECL detection kits (Millipore, USA) were applied to detect chemiluminescence of blots, and the intensity was quantified by scanning densitometry using Image J (NIH, Bethesda, $\mathrm{MD})$.

2.13. Statistical Analysis. Data are expressed as mean \pm SD The statistics was analyzed by a one-way analysis of variance (ANOVA) followed with Dunn's test via SPSS 16.0 software (IBM corporation, Armonk, USA). The significance was chosen as $P<0.05$.

\section{Results}

3.1. TM Caused Cell Damage in Hepatocellular Carcinoma Cells. A dose- and time-dependent cell viability reduction was noted in TM-treated cells, and the $48 \mathrm{~h} \mathrm{IC}_{50}$ were $5.3 \mathrm{mg} / \mathrm{mL}$ and $3.4 \mathrm{mg} / \mathrm{mL}$ in HepG2 and SMMC-7721 cells, respectively $(P<0.05$; Figures $1(\mathrm{a})$ and $1(\mathrm{~b}))$. Inhibitory effects of TM on cell migration ability were analyzed by a wound healing assay. Compared with nontreated cells, the migration abilities in cells were strongly abolished by TM incubation at 2.5 and $5 \mathrm{mg} / \mathrm{mL}$ (Figure 1(c)). Moreover, TM abolished the clonogenic abilities of hepatocellular carcinoma cells which began at $3 \mathrm{mg} / \mathrm{mL}$ and showed completely blocked activities at $5 \mathrm{mg} / \mathrm{mL}$ (Figure $1(\mathrm{~d})$ ).

3.2. TM Induced Apoptosis in Hepatocellular Carcinoma Cells. $12 \mathrm{~h}$ TM incubation enhanced the early and median apoptosis rate in HepG2 and SMMC-7721 cells at 2.5 and $5 \mathrm{mg} / \mathrm{mL}$ (Figure 2(a)). The maximum apoptosis rate reached $18.9 \%$ and $24.8 \%$ in HepG2 and SMMC-7721 cells, respectively (Figure $2(\mathrm{a})$ ). The activation of caspase-3, caspase-8, or caspase9 contributes to cell apoptosis and mitochondrial function $[21,22]$. Compared with nontreated cells, TM increased $12.3 \%, 94.1 \%$, and $44.2 \%$ activities of caspase- 3 , caspase- 8 , and caspase-9 in HepG2 cells, respectively $(P<0.05$; Figure $2(\mathrm{~b}))$. In SMMC-7721 cells, TM increased 22.4\%, 89.1\%, and $149.5 \%$ activities of caspase- 3 , caspase- 8 , and caspase-9, respectively $(P<0.01$; Figure 2(b)).

\subsection{TM Caused Apoptotic Alteration on Mitochondrial Func-} tion. Intracellular ROS accumulation is considered as a typical event during cell apoptosis [23]. At $6 \mathrm{~h}$ exposure to 2.5 and $5 \mathrm{mg} / \mathrm{mL}$ of TM, intracellular ROS levels were strongly enhanced in HepG2 and SMMC-7721 cells indicated by the increment of green fluorescence intensity (Figure 3(a)).

Apoptotic alternation on mitochondrial was noted during cell apoptosis, which served as a target for tumor therapy [24]. In both HepG2 and SMMC-7721 cells, compared with nontreated cells, $6 \mathrm{~h}$ TM incubation at doses of 2.5 and $5 \mathrm{mg} / \mathrm{mL}$ strongly decreased MMP evidenced by the enhancement in green fluorescence (JC-1 monomers) and reduction in red fluorescence (JC-1 aggregates) (Figure 3(b)). Furthermore, $24 \mathrm{~h}$ TM incubation resulted in a strong increase on cleavedPARP, Bad, and Bax levels, and a significant reduction on Bcl-2 expression in both HepG2 and SMMC-7721 cells (Figure 3(c)).

3.4. TM Inhibited HepG2- and SMMC-7721-Xenografted Tumor Growth. HepG2 and SMMC-7721-xenografted tumor nude mouse models were applied to further confirm the antihepatocellular carcinoma effects of TM. 14-day TM $(1 \mathrm{~g} / \mathrm{kg})$ administration robustly suppressed the HepG2 and SMMC7721-xenografted tumor growth in nude mice without influence on their body weights (Figures 4(a), 4(b), and 4(d)) (Figures 5(a), 5(b), and 5(d)). Compared with CTRL group, at the 14th day, TM decreased $66.5 \%$ and $71.9 \%$ tumor size in HepG2 $(P<0.05$; Figure 4(c)) and SMMC-7721xenografted tumor mice $(P<0.05$; Figure $5(\mathrm{c}))$, respectively. Similar to the results obtained in cell experiments, TM significantly enhanced the expressions of cleaved-PARP, Bax, and Bad in tumor tissues in both HepG2 (Figure 4(e)) and SMMC-7721-xenografted tumor mouse models (Figure 5(e)). 

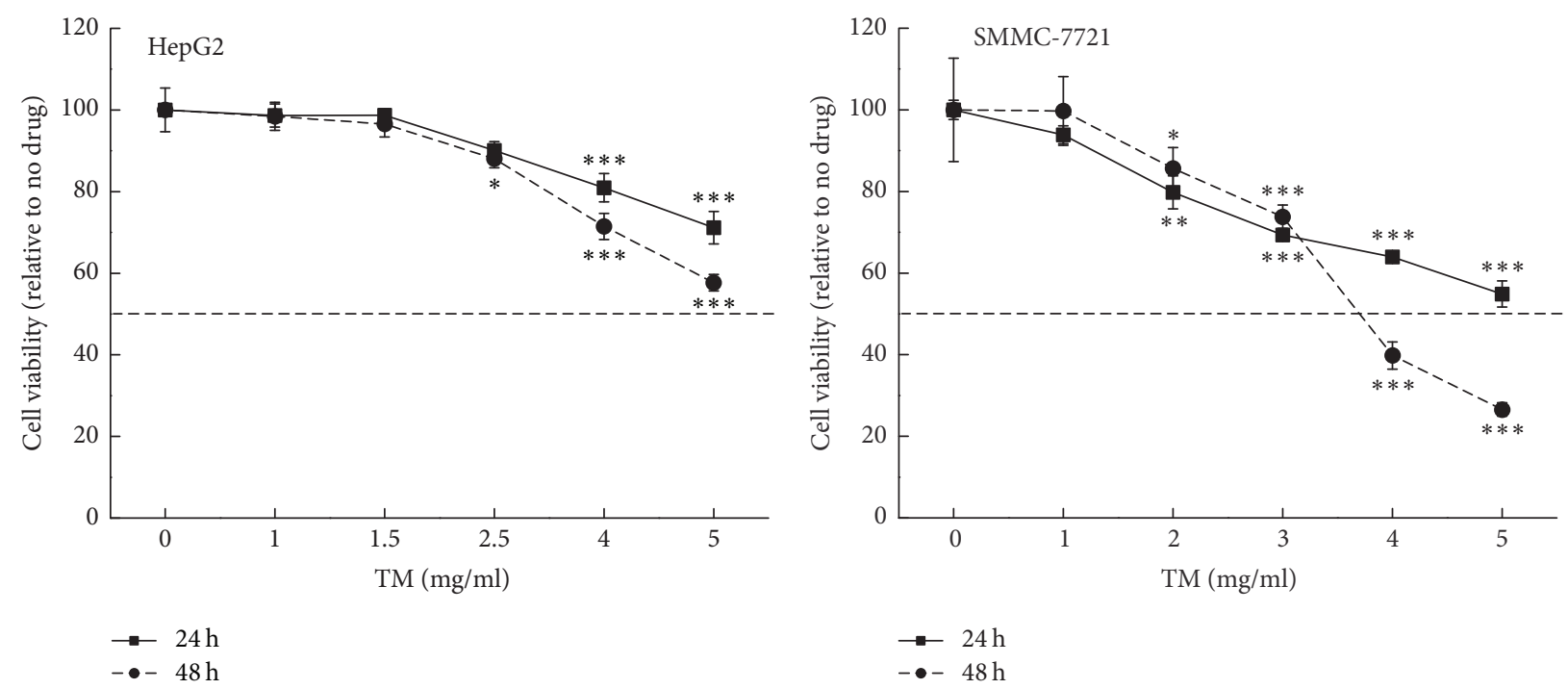

(a)

(b)
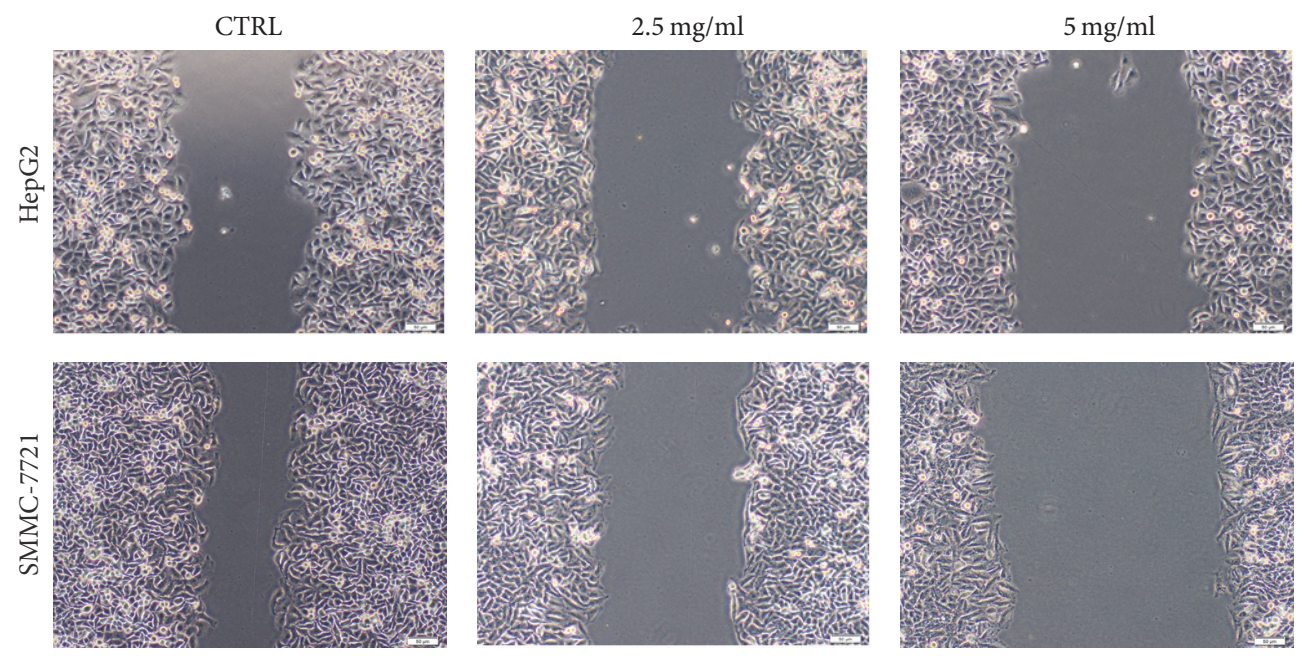

(c)

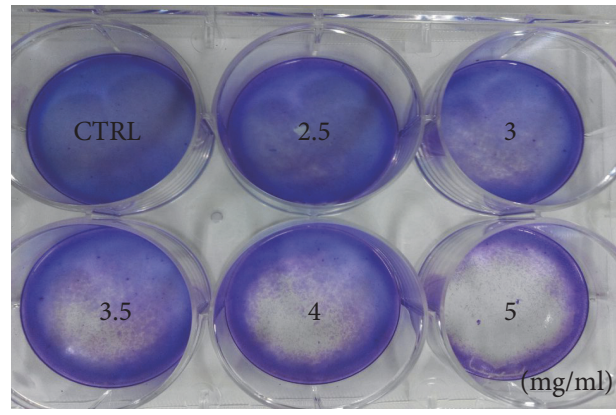

HepG2

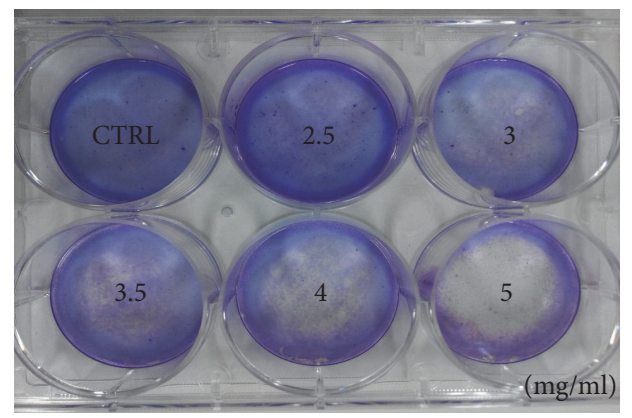

SMMC-7721

(d)

Figure 1: TM dose- and time-dependently reduced cell viability after $24 \mathrm{~h}$ and $48 \mathrm{~h}$ treatment in HepG2 (a) and SMMC-7721 (b) cells. Data are expressed as a percentage of that from corresponding control cells and means $\pm \mathrm{SD}(n=6) .{ }^{*} P<0.05,{ }^{* *} P<0.01$, and ${ }^{* * *} P<0.001$ versus control cells. (c) TM inhibited the migration ability of hepatocellular carcinoma cells determined via a wound healing assay (10x; scale bar: $100 \mu \mathrm{m})(n=3)$. (d) TM suppressed hepatocellular carcinoma cell proliferation analyzed via crystal violet staining $(n=3)$. 

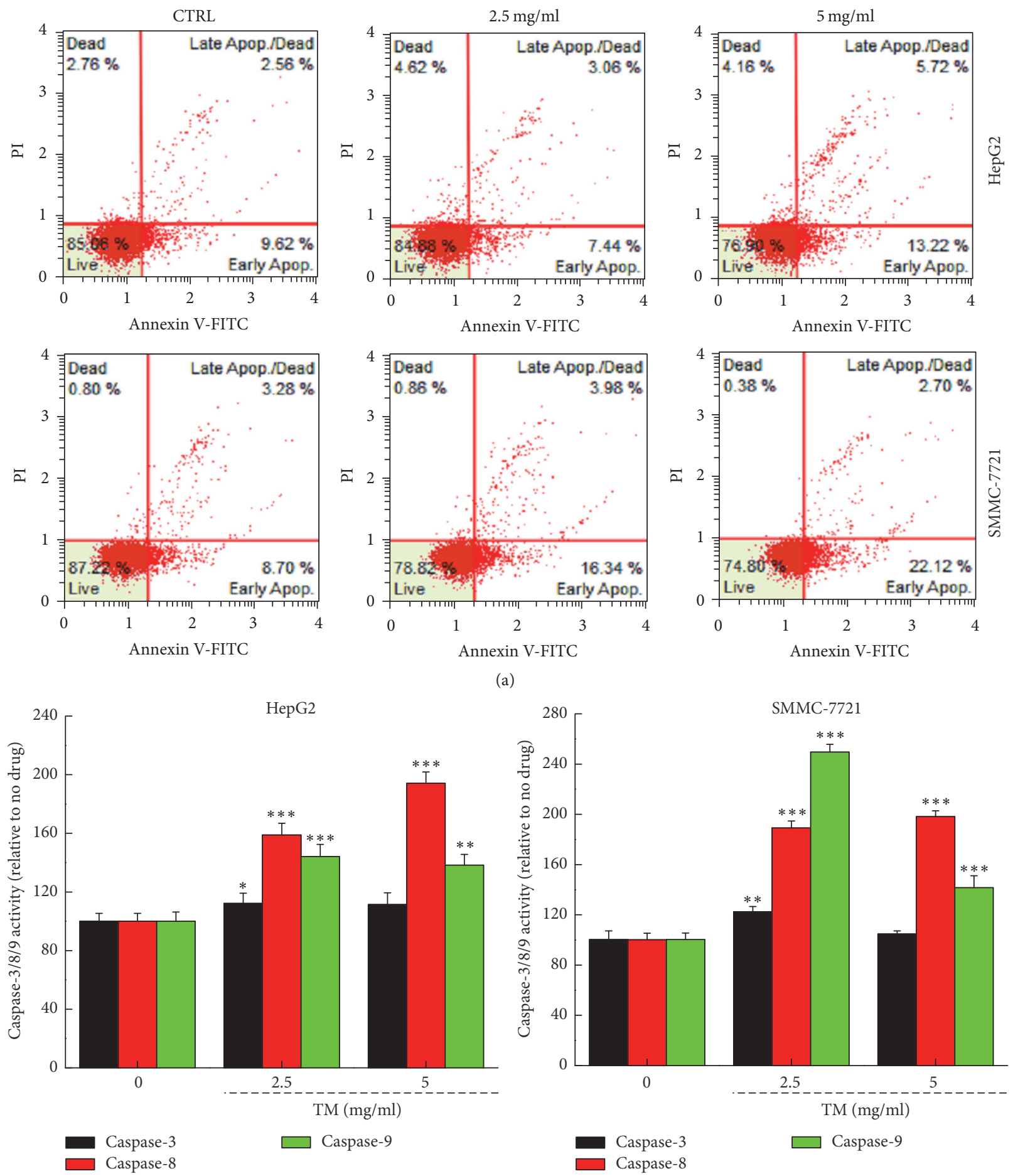

(b)

FIGURE 2: TM induced apoptosis in HepG2 and SMMC-7721 cells. (a) TM significantly enhanced the apoptotic rate in HepG2 and SMMC-7721 cells after $12 \mathrm{~h}$ incubation analyzing via flow cytometry $(n=3)$. (b) TM enhanced caspase- 3 , caspase-8, and caspase-9 activation in HepG2 and SMMC-7721 cells after $24 \mathrm{~h}$ exposure. Data are expressed as a percentage of that from corresponding control group and the means \pm SD $(n=6) .{ }^{*} P<0.05,{ }^{* *} P<0.01$, and ${ }^{* * *} P<0.001$ versus control cells. 

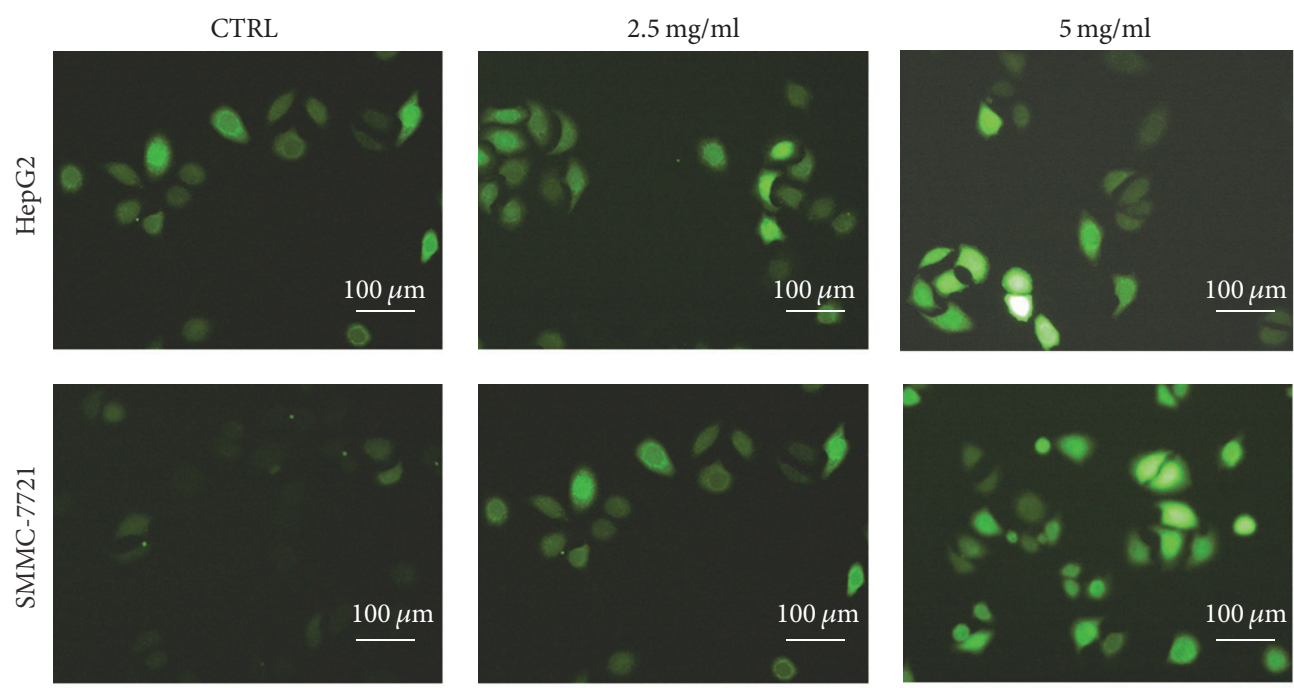

(a)
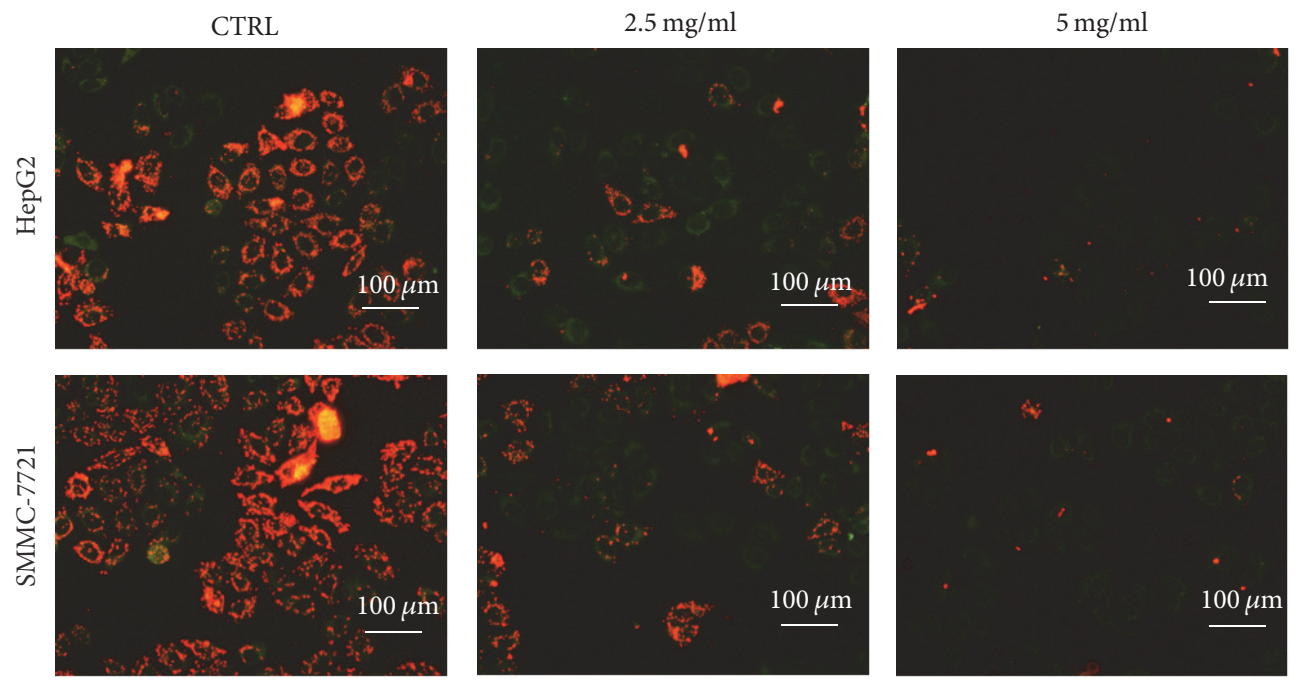

(b)

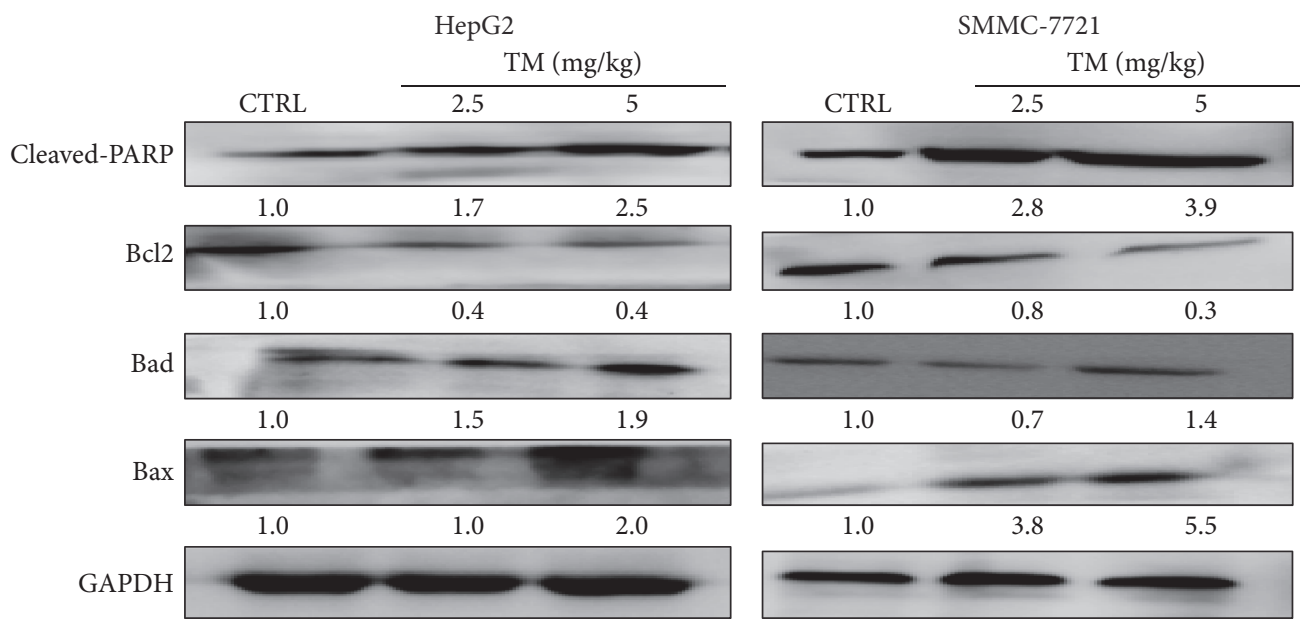

(c)

FIGURE 3: TM caused apoptotic alternations in mitochondrial function. (a) TM caused intracellular ROS accumulation in HepG2 and SMMC7721 cells analyzing via DCFH-DA staining after $6 \mathrm{~h}$ incubation (20x; scale bar: $100 \mu \mathrm{m})(n=3)$. (b) TM induced MMP dissipation detecting by JC-1 staining after $6 \mathrm{~h}$ incubation $(20 \mathrm{x}$; scale bar: $100 \mu \mathrm{m})(n=3)$. (c) $24 \mathrm{~h}$ TM exposure enhanced the expressions of cleaved-PARP, Bax, and Bad and suppressed the levels of Bcl-2. Quantification data of protein expressions were normalized by corresponding GAPDH and the average fold of band intensity was marked, respectively $(n=3)$. 

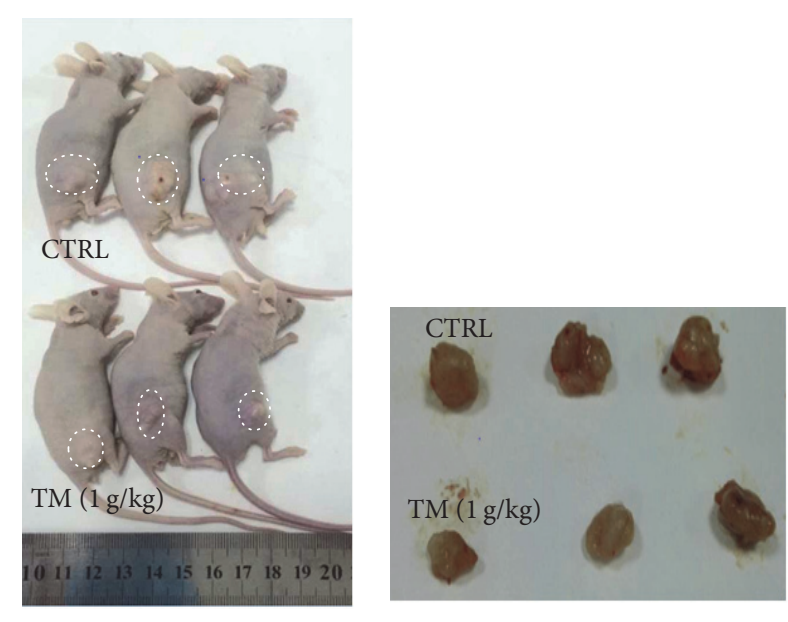

(a)

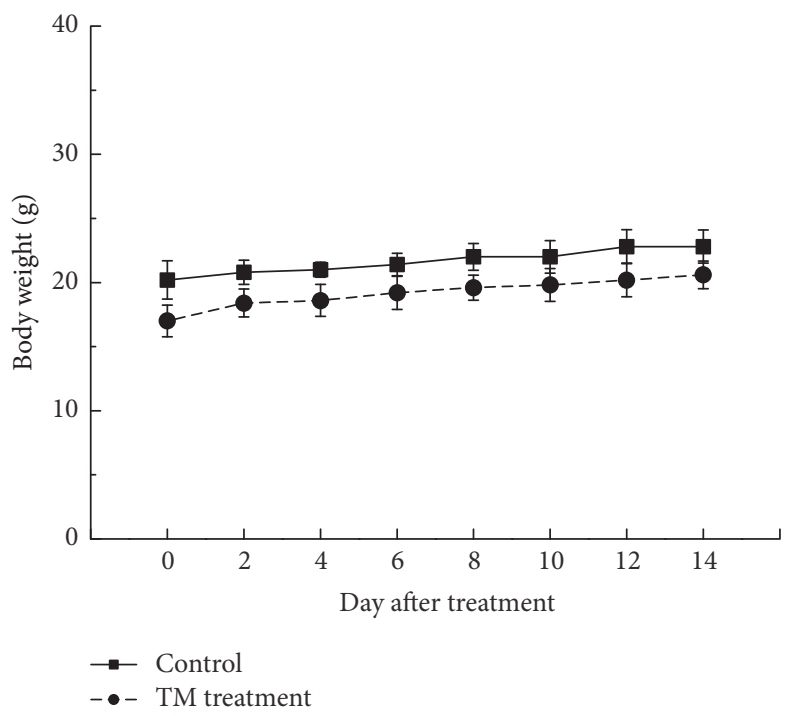

(d)

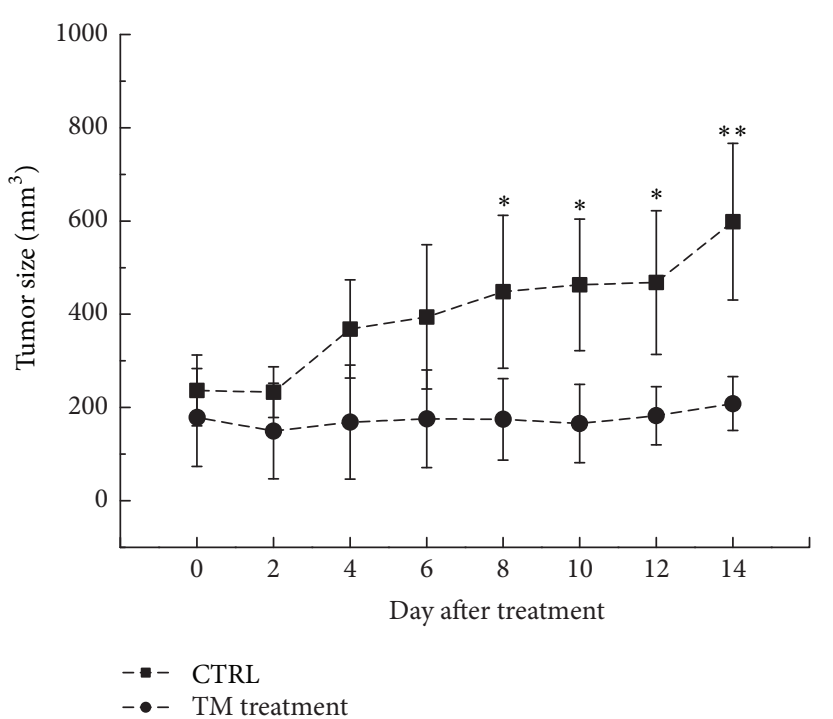

(c)

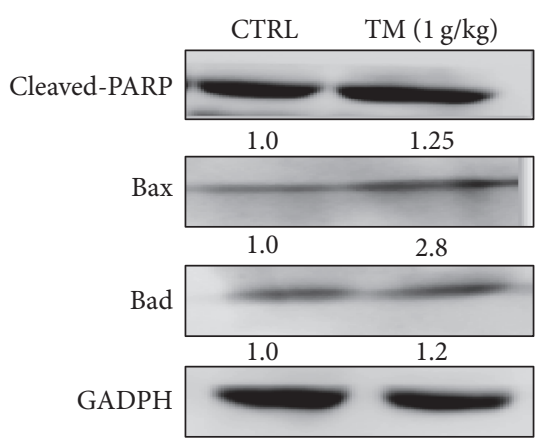

CTRL

TM $(1 \mathrm{~g} / \mathrm{kg})$
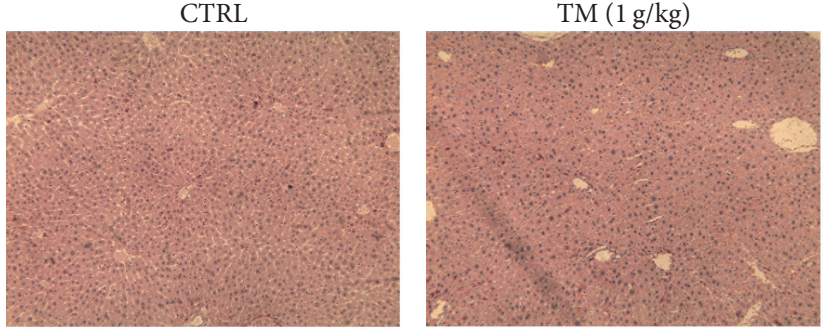

(f)

Figure 4: 14-day TM (1g/kg) administration suppressed tumor growth in HepG2-xenografted nude mouse models. (a) Tumor-possessing nude mice and (b) tumor tissues separated from CTRL and TM-treated groups. (c) Tumor volumes were measured every other day. Tumor size in the curve is expressed as mean $\pm \mathrm{SD}(n=3) .{ }^{*} P<0.05$ and ${ }^{* *} P<0.01$ versus control group. (d) Mean ( \pm SD) body weight of TM-treated and CTRL group $(n=3)$. (e) TM robustly enhanced the expressions of cleaved-PARP, Bad, and Bax in tumor tissues. Quantification data of protein expressions were normalized by corresponding GAPDH and the average fold of band intensity was marked, respectively $(n=3)$. (f) The histopathological examination of liver in tumor mouse models. 

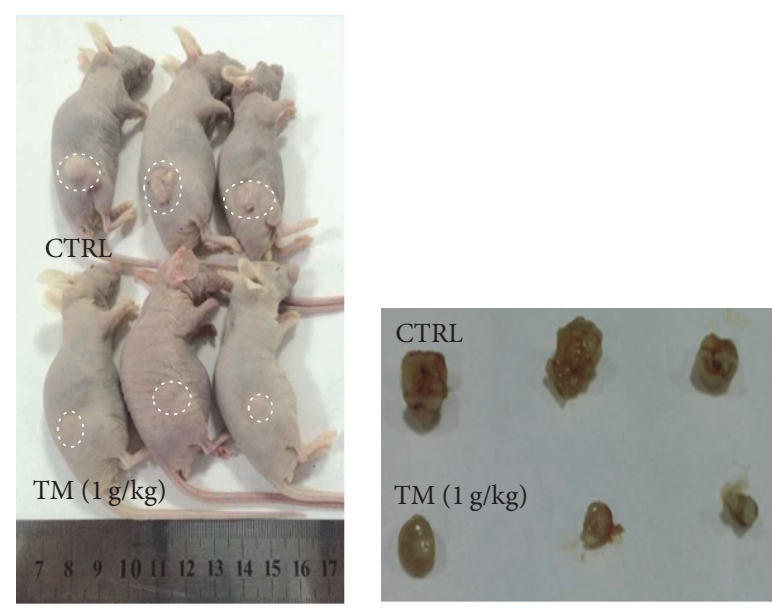

(a)

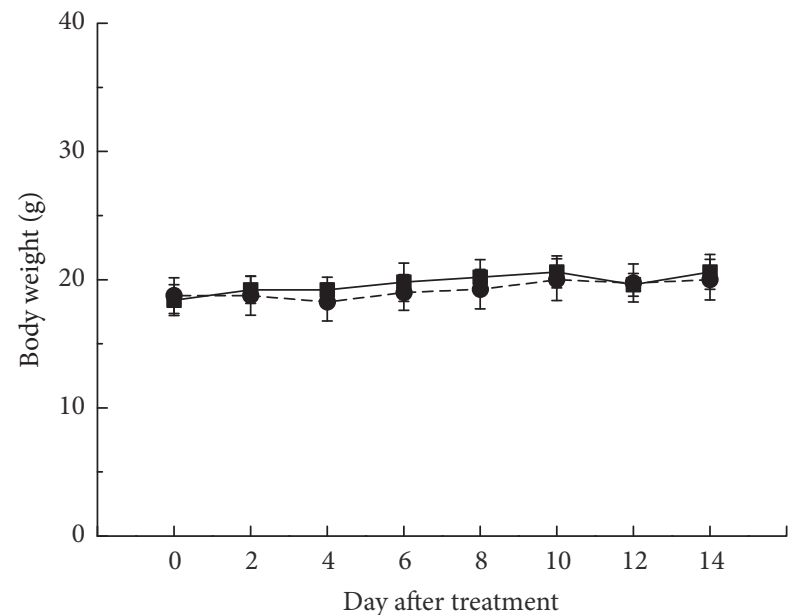

- Control

- - TM treatment

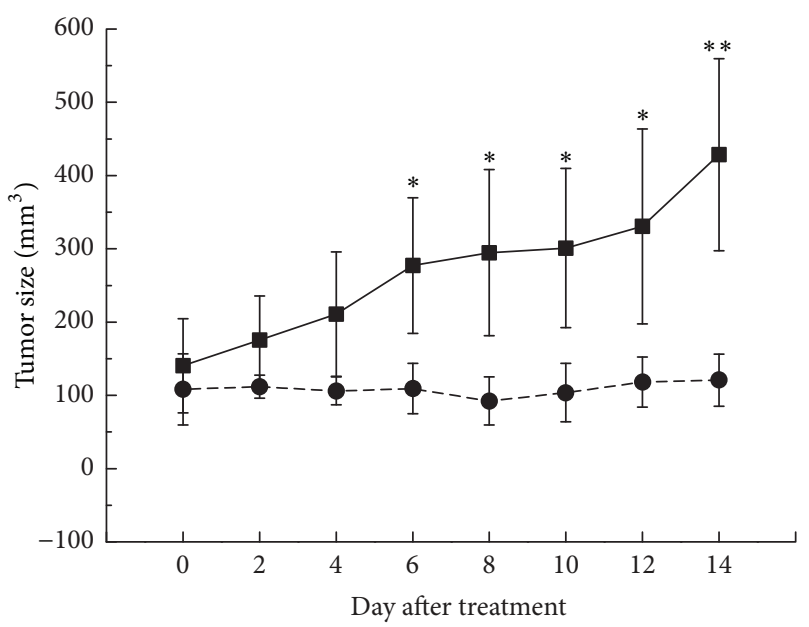

- CTRL

- - TM treatment
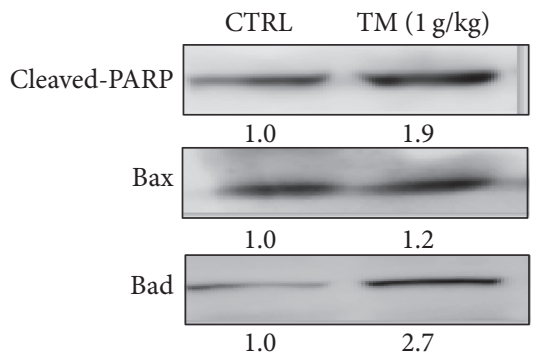

GADPH

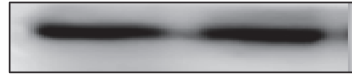

(e)

CTRL
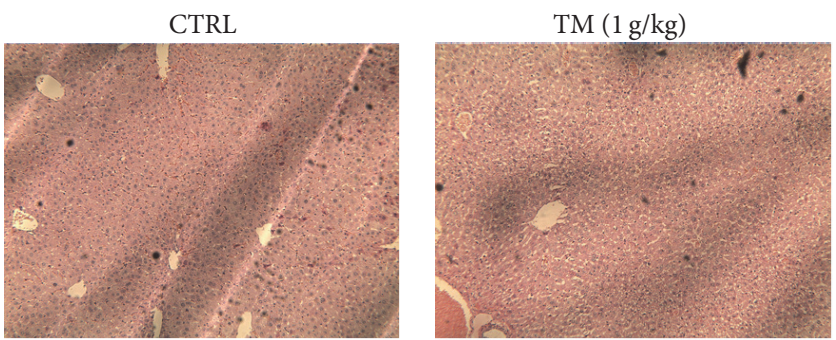

(f)

FIGURE 5: 14-day TM (1g/kg) administration suppressed tumor growth in SMMC-7721-xenografted nude mouse models. (a) Tumorpossessing nude mice and (b) tumor tissues separated from CTRL and TM-treated groups. (c) Tumor volumes were measured every other day. Tumor size in the curve is expressed as mean $\pm \mathrm{SD}(n=3) .{ }^{*} P<0.05$ and ${ }^{* *} P<0.01$ versus control group. (d) Mean ( $\left.\pm \mathrm{SD}\right)$ body weight of TM-treated and CTRL group $(n=3)$. (e) TM robustly enhanced the expressions of cleaved-PARP, Bad, and Bax in tumor tissues. Quantification data of protein expressions were normalized by corresponding GAPDH and the average fold of band intensity was marked, respectively $(n=3)$. (f) The histopathological examination of liver in tumor mouse models. 
Furthermore, H\&E staining revealed that TM had no significant influence on liver function in HepG2- and SMMC7721-xenografted tumor mice indicating TM is a safe agent (Figures 4(f) and 5(f)).

\section{Discussion}

We have studied the pharmacological activities of TM for years and confirmed that TM possesses antifatigue effects related to the modulation of AMPK linked antioxidation pathway [25]. Recently, our data show that TM strongly enhances immunity of cyclophosphamide-induced immunosuppressed mouse models associated with nuclear factor kappa B signaling. Based on these encouraging results, in the present experiments, the antihepatocellular carcinoma effects of TM were demonstrated in HepG2 and SMMC-7721 cells and related xenografted tumor mouse models. TM, a traditional Chinese herb medicine, contains multieffective components, which suggest multitargets in molecule signaling including apoptosis. Combining with previous data, the regulation of immune system may be involved in TMmediated proapoptotic effects. Furthermore, this "systemic targeting" will help TM to show its pharmacological functions in a much natural way, so that fewer adverse effects are expected. Moreover, as a folk tonic food, TM has been practiced by Asian people for years, further emphasizing its safety. In our acute toxic test, the safety of TM was confirmed suggesting no significant influences on animal behaviors and body organs (data not shown). Moreover, the crude nature of TM may explain its non-dose-dependent manner observed in the present experiments, which is similar to other herbal medicines [26].

In our study, TM decreased cell viability, increased ROS levels, and caused mitochondrial apoptotic alterations. Mitochondrial dysfunction is related to cell apoptosis and is considered as a target for anticancer drugs [27]. In hepatocellular carcinoma cells, TM not only reduced the dissipation of MMP, but also suppressed Bcl-2 levels and enhanced the expressions of Bax and Bad. Bcl-2, an integral membrane protein located in the outer membrane of mitochondria, is known as a biomarker of mitochondria dysfunction [28]. Apoptosis relies on the balance between antiapoptotic (Bcl2) and proapoptotic (Bax) proteins. Bax, a proapoptotic protein, induces the threshold at which mitochondria release Cyt C to promote cell death [29]. Similarly, in another experiment, we confirmed that C. militaris induces mitochondrial apoptosis in MCF-7 and HepG2 cells related to modulation on $\mathrm{Bcl}-2$ family protein expressions [30]. Oxidative stress is another factor responsible for mitochondrial function [31], during which intracellular ROS accumulation is noted. In mitochondria-dependent apoptosis, a positive feedback loop between intracellular ROS and mitochondria is reported, and ROS is released from mitochondria into cytoplasm [32, 33]. Collectively, the antihepatocellular carcinoma effects of TM are related to mitochondrial apoptotic pathway; however, the relationship between mitochondrial function and oxidative stress needs further investigation.
On the other hand, the reduced MMP promotes the release of apoptotic factors from mitochondria to cytoplasm, and Cyt $\mathrm{C}$ is the most typical one, which leads to caspase- 3 activation [34]. Caspase-3 is responsible for cell morphology and certain biochemical events including execution and completion of apoptosis [35]. As reported, caspase-3, activated by caspase- 8 and caspase- 9 , cleaves vital cellular proteins, leading to apoptosis via mitochondria-dependent pathway [36]. In hepatocellular carcinoma cells, TM strongly enhanced the activation of caspase- 3 , caspase- 8 , and caspase- 9 . Caspase- 8 , located mostly at the mitochondria, may directly cause the loss of MMP when it undergoes dimerization and cleaves itself to be an activation form [37]. The activated caspase8 can directly result in the cleavage of effector caspase in the cytosol [38]. All the results suggest that TM shows antihepatocellular carcinoma effects by inducing apoptosis via regulation caspase-family activities which may further target to mitochondria.

There are still some limitations in the present research. First, although we found the accumulation of intracellular ROS, its relationship with mitochondrial function is not clearly explained based on our data. Second, we only examined the antihepatocellular carcinoma effects of TM in HepG2 and SMMC-7721-xenografted tumor nude mouse models, which are hard to mimic the real satiation of tumor growth. Our ongoing experiments have focused on these limitations.

In conclusion, our study confirmed that TM induced apoptotic cell death in HepG2 and SMMC-7721 cells via caspase-dependent mitochondrial pathways. Our findings support further testing the antitumor effects of TM in other cell lines.

\section{Ethical Approval}

The experimental animal protocol was approved by the Animal Ethics Committee of Jilin University.

\section{Competing Interests}

The authors have declared that there is no conflict of interests.

\section{Authors' Contributions}

Yanzhen Wang, Yiling Chen, and Xinrui Zhang contribute equally to the project.

\section{Acknowledgments}

This work was supported by the Natural Science Foundation of China (Grant no. 81402955) and Science and Technology Key Project in Jilin Province of China (Grant nos. 20130201006ZY, 20150203002NY, and 20160204029YY).

\section{References}

[1] V. Santi, F. Trevisani, A. Gramenzi et al., "Semiannual surveillance is superior to annual surveillance for the detection of 
early hepatocellular carcinoma and patient survival," Journal of Hepatology, vol. 53, no. 2, pp. 291-297, 2010.

[2] A. G. Singal, A. Pillai, and J. Tiro, "Early detection, curative treatment, and survival rates for hepatocellular carcinoma surveillance in patients with cirrhosis: a meta-analysis," PLoS Medicine, vol. 11, no. 4, Article ID e1001624, 2014.

[3] D. Kuroda, H. Hayashi, H. Nitta et al., "Successful treatment for sorafenib-induced liver dysfunction: a report of case with liver biopsy," Surgical Case Reports, vol. 2, no. 1, p. 4, 2016.

[4] S. Somintara, V. Leardkamolkarn, P. Suttiarporn, and S. Mahatheeranont, "Anti-tumor and immune enhancing activities of rice bran gramisterol on acute myelogenous leukemia," PLoS ONE, vol. 11, no. 1, Article ID e0146869, 2016.

[5] J. Song, Y. Wang, M. Teng et al., "Cordyceps militaris induces tumor cell death via the caspasedependent mitochondrial pathway in HepG2 and MCF7 cells," Molecular Medicine Reports, vol. 13, no. 6, pp. 5132-5140, 2016.

[6] Y. Hou, X. Ding, W. Hou et al., "Anti-microorganism, antitumor, and immune activities of a novel polysaccharide isolated from Tricholoma matsutake," Pharmacognosy Magazine, vol. 9, no. 35, pp. 244-249, 2013.

[7] Y.-E. Kim, J.-W. Yang, C.-H. Lee, and E.-K. Kwon, "ABTS radical scavenging and anti-tumor effects of Tricholoma matsutake sing. (pine mushroom)," Journal of the Korean Society of Food Science and Nutrition, vol. 38, no. 5, pp. 555-560, 2009.

[8] L. You, Q. Gao, M. Feng et al., "Structural characterisation of polysaccharides from Tricholoma matsutake and their antioxidant and antitumour activities," Food Chemistry, vol. 138, no. 4, pp. 2242-2249, 2013.

[9] B.-S. Pan, Y.-K. Wang, M.-S. Lai, Y.-F. Mu, and B.-M. Huang, "Cordycepin induced MA-10 mouse Leydig tumor cell apoptosis by regulating p38 MAPKs and PI3K/AKT signaling pathways," Scientific Reports, vol. 5, Article ID 13372, 2015.

[10] K. Vannuvel, M. Van Steenbrugge, C. Demazy et al., "Effects of a sublethal and transient stress of the endoplasmic reticulum on the mitochondrial population," Journal of Cellular Physiology, vol. 231, no. 9, pp. 1913-1931, 2016.

[11] B. Sun, R. Ding, W. Yu, Y. Wu, B. Wang, and Q. Li, "Advanced oxidative protein products induced human keratinocyte apoptosis through the NOX-MAPK pathway," Apoptosis, vol. 21, no. 7, pp. 825-835, 2016.

[12] A. A. Guirguis, C. I. Slape, L. M. Failla et al., "PUMA promotes apoptosis of hematopoietic progenitors driving leukemic progression in a mouse model of myelodysplasia," Cell Death and Differentiation, vol. 23, no. 6, pp. 1049-1059, 2016.

[13] Q. Hu, D. Wu, W. Chen, Z. Yan, and Y. Shi, "Proteolytic processing of the caspase- 9 zymogen is required for apoptosomemediated activation of caspase-9," Journal of Biological Chemistry, vol. 288, no. 21, pp. 15142-15147, 2013.

[14] C. Damasio Dde, S. Nolte, L. P. Polak et al., "The lectin BJcuL induces apoptosis through TRAIL expression, caspase cascade activation and mitochondrial membrane permeability in a human colon adenocarcinoma cell line," Toxicon, vol. 90, pp. 299-307, 2014.

[15] A. M. Mileo and S. Miccadei, "Polyphenols as modulator of oxidative stress in cancer disease: new therapeutic strategies," Oxidative Medicine and Cellular Longevity, vol. 2016, Article ID 6475624, 17 pages, 2016.

[16] J. Hu, Q. Yu, F. Zhao et al., "Protection of Quercetin against Triptolide-induced apoptosis by suppressing oxidative stress in rat Leydig cells," Chemico-Biological Interactions, vol. 240, pp. 38-46, 2015.
[17] S. S. Kim, J. S. Lee, J. Y. Cho, Y. E. Kim, and E. K. Hong, "Process development for mycelial growth and polysaccharide production in Tricholoma matsutake liquid culture," Journal of Bioscience and Bioengineering, vol. 109, no. 4, pp. 351-355, 2010.

[18] M. R. Rover, P. A. Johnston, B. P. Lamsal, and R. C. Brown, "Total water-soluble sugars quantification in bio-oil using the phenol-sulfuric acid assay," Journal of Analytical and Applied Pyrolysis, vol. 104, pp. 194-201, 2013.

[19] K. L. Wojciechowski and D. M. Barbano, "Modification of the Kjeldahl noncasein nitrogen method to include bovine milk concentrates and milks from other species," Journal of Dairy Science, vol. 98, no. 11, pp. 7510-7526, 2015.

[20] P. Gomes, S. M. F. Torres, D. A. Plager, C. R. Jessen, and J. J. Lee, "Comparison of three staining methods to identify eosinophils in formalin-fixed canine skin," Veterinary Dermatology, vol. 24, no. 3, pp. 323-323.e72, 2013.

[21] J. Jia, S. Li, W. Gong, J. Ding, C. Fang, and Z. Quan, "Mda-7/IL24 induces apoptosis in human GBC-SD gallbladder carcinoma cells via mitochondrial apoptotic pathway," Oncology Reports, vol. 25, no. 1, pp. 195-201, 2011.

[22] T.-H. Ying, S.-F. Yang, S.-J. Tsai et al., "Fisetin induces apoptosis in human cervical cancer HeLa cells through ERK1/2mediated activation of caspase-8-/caspase-3-dependent pathway," Archives of Toxicology, vol. 86, no. 2, pp. 263-273, 2012.

[23] L. Wang, T. Hu, J. Shen et al., "Miltirone induced mitochondrial dysfunction and ROS-dependent apoptosis in colon cancer cells," Life Sciences, vol. 151, pp. 224-234, 2016.

[24] A.-C. Cheng, M.-F. Lee, M.-L. Tsai et al., "Rosmanol potently induces apoptosis through both the mitochondrial apoptotic pathway and death receptor pathway in human colon adenocarcinoma COLO 205 cells," Food and Chemical Toxicology, vol. 49, no. 2, pp. 485-493, 2011.

[25] Q. Li, Y. Wang, G. Cai et al., "Antifatigue activity of liquid cultured Tricholoma matsutake mycelium partially via regulation of antioxidant pathway in mouse," BioMed Research International, vol. 2015, Article ID 562345, 10 pages, 2015.

[26] X.-N. Jia, W. Dong, W.-D. Lu, L.-Z. Guo, and Y.-X. Wei, "In vivo immunostimulatory and tumor-inhibitory activities of polysaccharides isolated from solid-state-cultured Trametes robiniophila murrill," World Journal of Microbiology and Biotechnology, vol. 25, no. 11, pp. 2057-2063, 2009.

[27] F. Villarroel-Espíndola, C. Tapia, R. González-Stegmaier, I. I. Concha, and J. C. Slebe, "Polyglucosan molecules induce mitochondrial impairment and apoptosis in germ cells without affecting the integrity and functionality of sertoli cells," Journal of Cellular Physiology, vol. 231, no. 10, pp. 2142-2152, 2016.

[28] A. Gross, "BCL-2 family proteins as regulators of mitochondria metabolism," Biochimica et Biophysica Acta (BBA)Bioenergetics, vol. 1857, no. 8, pp. 1243-1246, 2016.

[29] Y. Cui, P. Lu, G. Song, Q. Liu, D. Zhu, and X. Liu, "Involvement of PI3K/Akt, ERK and p38 signaling pathways in emodinmediated extrinsic and intrinsic human hepatoblastoma cell apoptosis," Food and Chemical Toxicology, vol. 92, pp. 26-37, 2016.

[30] D. Wang, J. Lu, Y. Liu et al., "Liquiritigenin induces tumor cell death through mitogen-activated protein kinase- (MPAKs-) mediated pathway in hepatocellular carcinoma cells," BioMed Research International, vol. 2014, Article ID 965316, 11 pages, 2014.

[31] I. B. Afanas'ev, "Signaling functions of free radicals superoxide \& nitric oxide under physiological \& pathological conditions," Molecular Biotechnology, vol. 37, no. 1, pp. 2-4, 2007. 
[32] J. K. Freed, A. M. Beyer, J. A. Logiudice, J. C. Hockenberry, and D. D. Gutterman, "Ceramide changes the mediator of flowinduced vasodilation from nitric oxide to hydrogen peroxide in the human microcirculation," Circulation Research, vol. 115, no. 5, pp. 525-532, 2014.

[33] J. Ma, Y. Feng, Y. Liu, and X. Li, "PUMA and survivin are involved in the apoptosis of HepG2 cells induced by microcystin-LR via mitochondria-mediated pathway," Chemosphere, vol. 157, pp. 241-249, 2016.

[34] Q. Bao and Y. Shi, "Apoptosome: a platform for the activation of initiator caspases," Cell Death and Differentiation, vol. 14, no. 1, pp. 56-65, 2007.

[35] M. Shrivastava and V. Subbiah, "Elevated caspase 3 activity and cytosolic cytochrome c in NT2 cybrids containing amyotrophic lateral sclerosis subject mtDNA," International Journal of Neuroscience, vol. 126, no. 9, pp. 839-849, 2016.

[36] H. Li, J. Tong, J. Bao, D. Tang, W. Tian, and Y. Liu, "Hematoporphyrin monomethyl ether combined with $\mathrm{He}-\mathrm{Ne}$ laser irradiation-induced apoptosis in canine breast cancer cells through the mitochondrial pathway," Journal of Veterinary Science, vol. 17, no. 2, pp. 235-242, 2016.

[37] K. H. Leong, C. Y. Looi, X. M. Loong et al., "Cycloart-24-ene-26ol-3-one, a new cycloartane isolated from leaves of Aglaia exima triggers tumour necrosis factor-receptor 1-mediated caspasedependent apoptosis in colon cancer cell line," PLOS ONE, vol. 11, no. 4, Article ID e0152652, 2016.

[38] X. Tang, Z. Xing, H. Tang, L. Liang, and M. Zhao, "Human cell-death-inducing DFF45-like effector C induces apoptosis via caspase-8," Acta Biochimica et Biophysica Sinica, vol. 43, no. 10, pp. 779-786, 2011. 


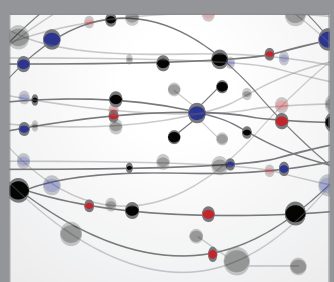

The Scientific World Journal
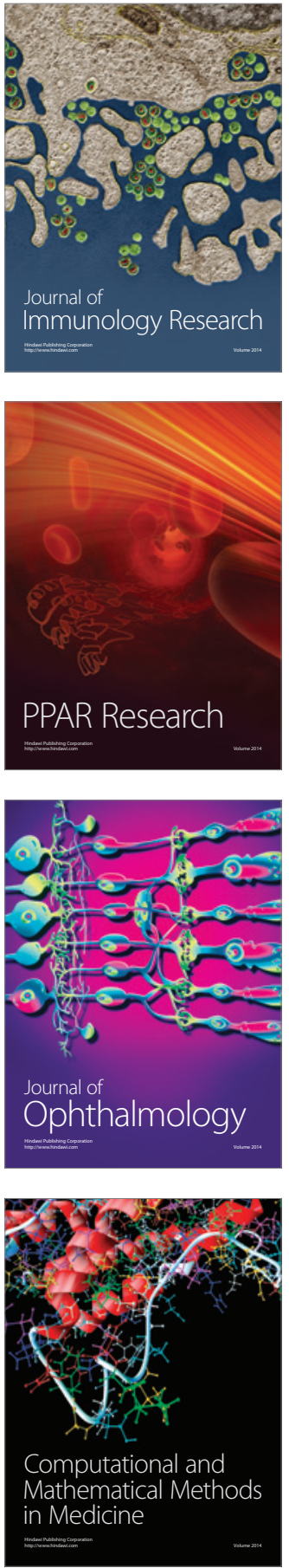

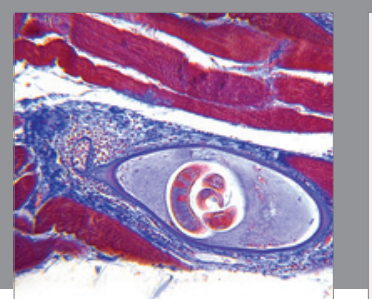

Gastroenterology Research and Practice

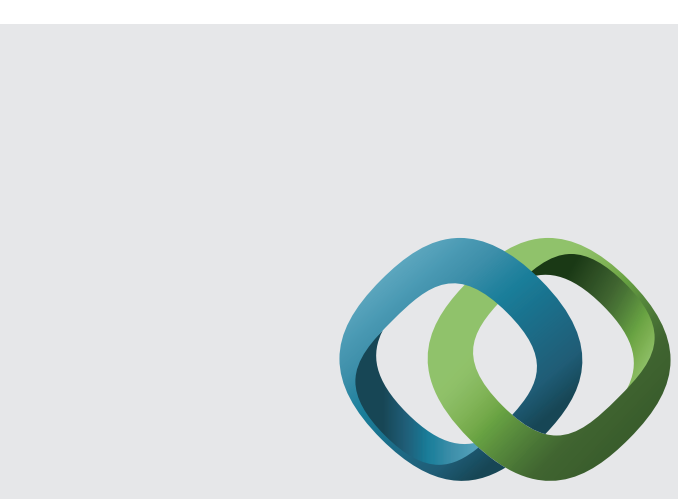

\section{Hindawi}

Submit your manuscripts at

http://www.hindawi.com
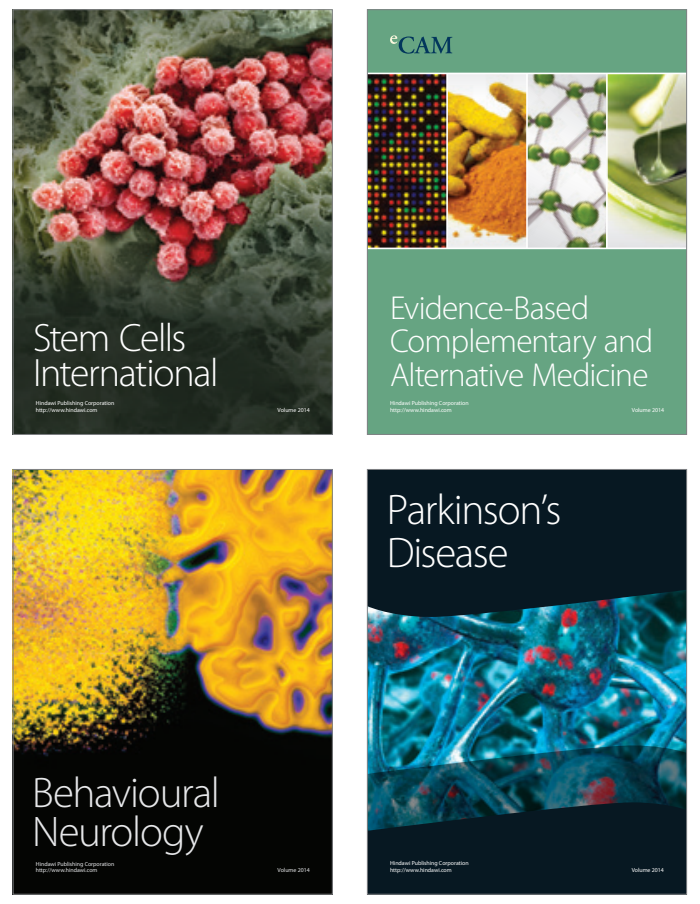
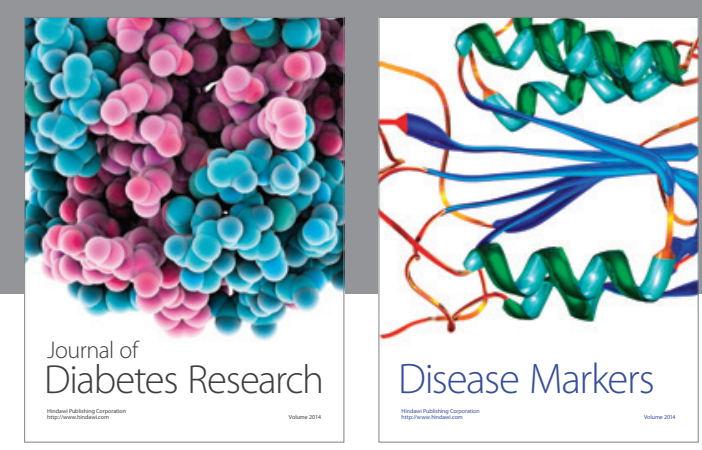

Disease Markers
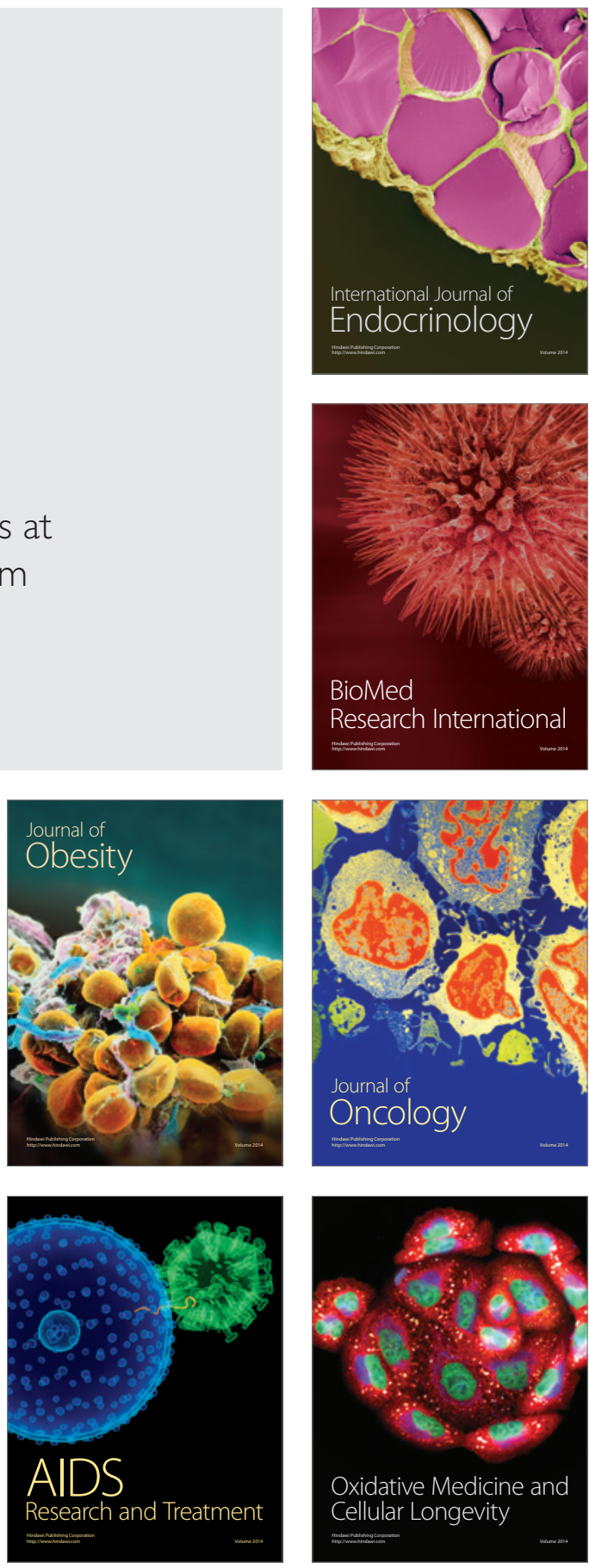